\title{
Contribution of PMSG based Small Wind Generation Systems to Provide Voltage Control in Low Voltage Networks
}

\author{
J. M. Rodrigues, F. O. Resende, C. L. Moreira
}

\begin{abstract}
This paper proposes technical solutions that can be implemented in variable speed permanent magnet synchronous generators driven wind turbine systems aiming to mitigate high voltage problems in low voltage MicroGrids by controlling the active power output. Due to the limited control capability of these systems, controlling the output power to prevent voltage rise will require the local accommodation of the generation surplus. For this purpose, additional control functionalities are developed to be integrated in the control systems of the power electronic based interfaces. Their performance is evaluated through numerical simulations performed in Matlab $^{\circledR} /$ Simulink $^{\circledR}$ environment and considering the detailed models of the power electronic converters. The results obtained demonstrate the effectiveness of the proposed control functionalities.
\end{abstract}

Index Terms-MicroGrids, microgeneration systems, small scale wind systems, voltage control, power electronic converters, permanent magnet synchronous generator.

\section{INTRODUCTION}

$F_{c}^{\circ}$ OLLOWING the increasing penetration of Distributed Generation (DG) in Medium Voltage (MV) distribution networks, the dissemination of small size and modular microgeneration systems connected to the Low Voltage (LV) networks will provide an important contribution to face the continuous demand growth. The need of reducing greenhouse gas emissions, recent technological developments related with the improvement of systems efficiency and the possibility of exploiting Renewable Energy Sources (RES) are important issues that are contributing for the deployment of microgeneration systems in LV networks [1-3].

However, increasing penetration levels of microgeneration systems require tackling several technical issues regarding mainly the LV networks management and control. In order to face these challenges and to best profit their potential benefits, active and coordinated control strategies need to be implemented in order to control all the active elements connected to the LV network. For this purpose, the MicroGrid (MG) concept should be adopted [2], [3].

This work was supported by Fundo de Apoio à Inovação (FAI) under the framework of the Project REIVE - Redes Eléctricas Inteligentes com Veículos Eléctricos (SmartGrids with Electric Vehicles).

The authors are with INESC-Porto (Institute of Engineering and Computer Systems). C. L. Moreira is also with FEUP (Faculty of Engineering of Porto University), Porto, Portugal (contact e-mail: fresende@inescporto.pt).
The MG concept comprises a LV distribution network with loads (some of them being controllable), small modular generation units and storage devices connected to it through power electronic interfaces, operating in a controlled coordinated way by means of using advanced management and control systems supported by a proper communication infrastructure. Therefore, the MG can be operated as a coordinated entity both in interconnected and islanded mode [2], [3]. The MG is centrally controlled and managed by the MGCC installed at the MV/LV secondary substation, which is responsible to head the MG hierarchical control system. For this purpose the MGCC includes several key functions that support adequate technical and economical management policies and allow providing set points to the second control level comprising Microsource Controllers (MC) and Load Controllers (LC), in order to control locally the controllable microgeneration units and the responsive loads, respectively.

However, in spite of the MG control and management capabilities, the control of voltage profiles in LV distribution networks can become a difficult task. Since this kind of networks are characterized by having high $\mathrm{R} / \mathrm{X}$ ratios, high voltage problems can arise from the active power flow in the opposite direction as a result of the injected active power from the microgeneration systems, especially in radial grids with long branches and low load density [4]. Under this context, a special attention should be given to microgeneration systems exploiting RES, such as photovoltaic and micro wind generation systems, due to the limited control capability of the active power generation. In addition, these systems are usually equipped with Maximum Power Point Tracking (MPPT) systems in order to increase efficiency according to the primary resource availability. Thus, when the generation levels are high during periods of low local consumption, rise voltage problems can arise and therefore the microgeneration system can be switched-off by means of their own maximum voltage protection systems [8], [9]. In order to overcome this problem, innovative control strategies need to be developed to control the voltage profile based on the injected active power control from both photovoltaic and micro wind generation systems. However, only the micro wind generation system is considered in this work.

Permanent Magnet Synchronous Generator (PMSG) are becoming very popular in wind power applications specially for gearless drive systems with advantages such as small size, 
less weight, flexible design [9] and attractive low cost [10], when compared with other rotating machines with similar ratings. For small scale wind applications (some kilowatts) low speed multi-pole PMSG are certainly the most convenient technology since they have a better reliability and increased efficiency without gearboxes or external excitation systems [9], [11]-[14]. In addition, PMSG are well adapted for variable speed operation intended to increase the system efficiency by maximizing the energy extracted from the incoming wind speed. The wind turbine mechanical power is then converted to a variable voltage and variable frequency power output, requiring therefore a full size ac-dc-ac power electronic based interface to connect the PMSG to the grid. A proper control scheme is also required to deliver the maximum output power with constant grid voltage and frequency [15].

Thus, in this paper, the control capabilities of power electronic converters are exploited to implement additional control functionalities aiming to control the active power supplied to the LV grid by micro wind generation systems equipped with PMSG in order to keep the voltage levels within acceptable limits. For this purpose, three technical solutions are proposed. The implementation of these control strategies in PMSG based micro wind generation systems under the framework of the MG concept aims to provide capability for supporting two complementary control philosophies:

- Local control, being the active power supplied to the grid adjusted autonomously based on the voltage level measured locally;

- Hierarchical/centralized control in which the active power supplied to the grid follows a given set-point sent by the MGCC to the MC.

The local control provides an autonomous and fast response regarding voltage control, but it may be not sufficient to assure the MG management and control in optimum operating conditions. A suitable coordination involving both control philosophies is thereby required. However, since the scope of this research is focused on the performance evaluation of the proposed technical solutions, only the local control is addressed.

\section{The Mathematical Model OF THE SMall Wind GENERATION SYSTEM EQUIPPED WITH PMSG}

As already mentioned previously, a PMSG driven wind turbine system is connected to the LV network through a full size ac-dc-ac power electronic converter. For this purpose, several topologies together with control schemes varying in cost and complexity have been proposed and investigated, as described in [16].

Several structures, involving different levels of complexity, can be used focusing in particular the ac-dc conversion system, which can be either a Pulse WidthModulation (PWM) voltage source rectifier or a simple diode bridge connected to a dc-dc boost converter. Since no external excitation current is required, a diode bridge rectifier without control systems can be used at PMSG terminals, being the major cost benefit in using PMSG based wind turbine generation systems for small scale applications [17]-[20]. In [14] a comparative study is presented regarding the tradeoffs between structure complexity and energy efficiency. The authors conclude that the diode bridge with a dc-dc boost converter is a cheaper and simpler solution for which results are quite satisfactory for small scale wind applications. Therefore, this structure together with a Voltage Source Inverter (VSI) [17], [18] was adopted in this work to connect the PMSG to the LV network, as it can be observed from Fig. 1.

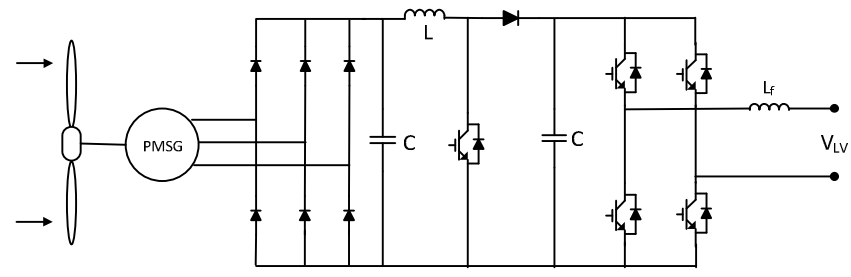

Fig. 1: Configuration of the micro wind generation systems equipped with PMSG [21].

The micro wind generation system comprises the PMSG driven by a fixed pitch wind turbine and the typical power electronic topology involving the diode bridge rectifier followed by the dc-dc boost converter and the current controlled PWM single-phase two-level VSI connected to the LV grid. This system topology is recommended to be integrated with both strong and weak ac systems, assuming the system operation under normal operating conditions [16].

The PMSG three-phase variable voltage variable frequency power output is rectified in the diode bridge. Since the dc-link voltage of the diode rectifier side is a variable dc voltage, resulting from the PMSG variable speed, the dc-dc boost converter adapts the rectified voltage in order to keep constant the VSI dc-link voltage, which is then inverted into a singlephase, $50 \mathrm{~Hz}$ voltage waveform by using a current controlled VSI. The PMSG is then decoupled from the grid by the voltage sourced dc-link, providing thus the required control flexibility for the micro wind generation system equipped with the PMSG and enabling the fast control of the active and reactive power.

A brief description of the PMSG based micro wind generation system main components is presented in the following sections.

\section{A. The Wind Turbine Model}

The amount of mechanical power that can be extracted from the incoming wind speed is specific to each wind turbine and can be calculated as [22]:

$$
P_{m}=\frac{1}{2} \rho A C_{p} v^{3}
$$

Where:

$P_{m}$ is the mechanical power (W);

$\rho$ is the air density $\left(\mathrm{kg} / \mathrm{m}^{3}\right)$;

$A$ is the swept area $\left(\mathrm{m}^{2}\right)$;

$v$ is the incoming wind speed $\left(\mathrm{ms}^{-1}\right)$; 
$C_{p}$ is the power coefficient of the wind turbine.

For a fixed pitch wind turbine, the power coefficient depends on the tip speed ratio, $\lambda$, which is given by:

$\lambda=\frac{\omega_{m} R}{v}$

Where:

$\omega_{m}$ is the turbine rotation speed (rpm);

$R$ is the radius of the turbine blade $(\mathrm{m})$.

If the rotor speed is adjusted according to the wind speed variations, the tip speed ratio can be kept at the optimal operating point, $\lambda_{\text {opt }}$, yielding the maximum aerodynamic efficiency, $C_{p \max }$, and therefore the maximum turbine output power. Thus, the optimum shaft speed (rpm) can be obtained as:

$\omega_{m o p t}=\frac{\lambda_{o p t}}{R} v$

Variable speed operation aims to maximize the mechanical power extracted from the incoming wind speed by tracking the shaft speed to the target speed corresponding to the optimum tip speed ratio.

\section{B. The mathematical model of PMSG}

Mathematical models to represent the dynamic behavior of PMSG used in small scale wind power applications have been developed previously and reported on the available literature. Usually the machine electrical equations can be written in the rotor $d-q$ reference frame in terms of voltages and currents as follows [23]-[25]:

$$
\begin{aligned}
& v_{d}=R_{s} i_{d}-\omega_{r} L_{q} i_{q}+L_{d} \frac{d i_{d}}{d t} \\
& v_{q}=R_{s} i_{q}+\omega_{r} L_{d} i_{d}+L_{d} \frac{d i_{q}}{d t}+\omega_{r} \Phi_{m}
\end{aligned}
$$

\section{Where:}

$L_{d}, L_{d}$ are the $d$ and $q$ axis inductances $(\mathrm{H})$;

$R$ is the stator winding resistance $(\Omega)$;

$i_{d}, i_{q}$ are the $d$ and $q$ axis machine current (A);

$v_{d}, v_{q}$ are the $d$ and $q$ axis machine voltages $(\mathrm{V})$;

$\Phi_{m}$ is the flux linkage established by the permanent magnets in the stator windings $(\mathrm{Wb})$;

$\omega_{r}$ is the angular frequency of the stator voltage $(\mathrm{rad} / \mathrm{s})$;

For a gearless PMSG, the angular frequency of the stator voltage is related with the turbine shaft speed, $\omega_{m}(\mathrm{rad} / \mathrm{s})$ as:

$\omega_{r}=\frac{p}{2} \omega_{m}$
Where $p$ is the number of poles of the PMSG.

The electromagnetic torque in the rotor is written as:

$T_{e}=\frac{3}{2} \times \frac{p}{2}\left[\left(L_{d}-L_{q}\right) i_{d} i_{q}+\Phi_{m} i_{q}\right]$

The mechanical equation taking into account the combined inertia and load viscous friction of the PMSG and wind turbine is given by:

$T_{e}-T_{m}=J \frac{d \omega_{r}}{d t}+F \omega_{r}$

Where

$T_{m}$ is the mechanical torque on the shaft (N.m);

$T_{e}$ is the electromagnetic torque (N.m);

$J$ is the combined inertia of the PMSG based wind system $\left(\mathrm{kg} / \mathrm{m}^{2}\right)$;

$F$ is the friction coefficient of the PMSG based wind system (N.m.s/rad).

\section{The dc-dc boost converter and control scheme}

Due to its low cost and control simplicity, the dc-dc boost converter topology together with control scheme presented in [26] was adopted in this work. This is basically a switching mode power device comprising a rectifier diode, a power transistor with the anti-parallel diode, an inductor and a smoother capacitor, as it can be observed from Fig. 2.

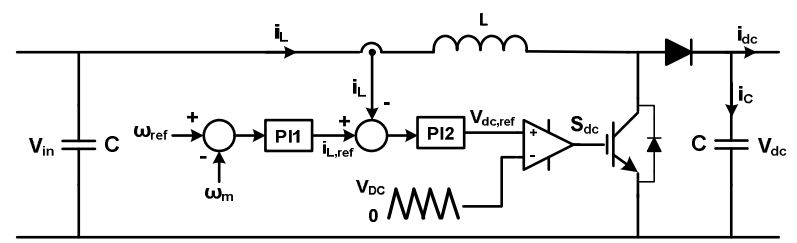

Fig. 3: The topology of the dc-dc boost converter and control scheme

This converter acts as an interface between the diode rectifier output and the VSI by employing PWM control techniques. Then, the dc-link is divided into two levels: The dc-link voltage at the output terminals of the diode rectifier, which is a variable dc voltage, and the dc-link voltage at the input terminals of the VSI, which is fed from a fixed dc voltage. The dc-link voltage of the diode rectifier side is controlled by varying the switch duty cycle of the dc-dc boost converter, allowing thus to control the PMSG rotor speed by regulating the boost converter inductance current, $i_{L}$. Therefore, the proposed control scheme aims to control the shaft speed of the PMSG driven wind turbine in order to keep the tip speed ratio at the optimal operating point for all wind speeds.

For this purpose, two Proportional-Integral (PI) controllers are used. The reference of the inductance current is obtained through the PI1 controller that regulates the PMSG speed to the target rotor speed. The reference of the inductance current is then compared with its actual value, being the error used by the PI 2 controller in order to derive the dc voltage reference that controls the switching duty cycle of the dc-dc boost converter [26]. 
Indeed, this control scheme allows controlling the extracted power of the PMSG driven wind turbine, such that the speed of the generator tracks the target rotor speed, $\omega_{\text {ref }}$, which is derived from the optimal power versus rotating speed characteristic of the PMSG driven wind turbine using the measured wind speed. The rotor speed is also measured and compared to the optimal rotor wind speed, being the resulting error used to control the power interface [22]. Due to its simplicity, this MPPT algorithm was adopted in this work.

\section{The grid side converter and control structure}

The grid side converter, operating at the grid frequency (50 $\mathrm{Hz}$ ) involves a single phase full bridge IGBT inverter [15] and the control scheme presented in Fig. 3.

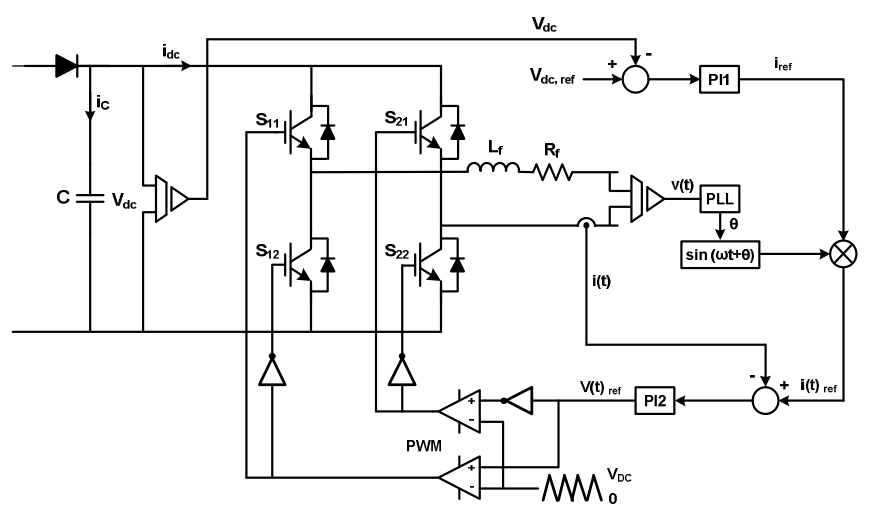

Fig. 3: Inverter topology and control structure

The control strategy aims basically to regulate the dc-link voltage at the input terminals of the VSI and to operate the PMSG based micro wind system with a unitary power factor in order to maximize the active power delivered to the grid. This has been a common procedure in LV networks. The sinusoidal current mode control [27] was also adopted to reduce the Total Harmonic Distortion (THD) of the system output current. The controller is implemented with constant switching frequency imposed by the triangular carrier signal in order to perform selective harmonic elimination, thereby reducing the harmonic spectrum of the output current and also the system losses [17], [18].

According to this control scheme, the active power control is performed by regulating both the magnitude and phase of the fundamental output current such that it tracks a sinusoidal reference current which is in phase with the grid voltage. For this purpose, a current reference, $I_{r e f}$, is derived from the error of the dc-link voltage through the PI1 controller and used to define the magnitude of the sinusoidal reference current together with the phase angle of the voltage grid, which is detected by using a Phase Look Loop (PLL), as it can be observed from Fig. 3. Based on the error between this sinusoidal reference current and the corresponding actual value, the PI 2 controller regulates the output current by providing a sinusoidal voltage reference that is used on the PWM generator to define proper pulse signals to control the IGBT switching.

\section{Advanced Control Features to Provide Voltage CONTROL}

As already mentioned previously, the presence of increasing levels of micro wind generation systems in LV networks will contribute to voltage rise, especially in weak systems comprising feeders with low $\mathrm{X} / \mathrm{R}$ ratio and during periods with high generation levels and low consumption. Since these systems are usually controlled for maximum power point operation, they can be tripped out by their own overvoltage protection systems under the above mentioned circumstances. Thus, the proposed control strategies aim to provide additional control capabilities of PMSG driven wind systems, allowing them to control/limit the active power injected in LV networks when voltage rises above acceptable limits. These high level control functionalities will contribute to improve the LV network operating conditions by providing a dynamic local control based on the following approaches:

- Control of the PMSG speed in order to decrease aerodynamic efficiency;

- Using the dump load system to dissipate the power generation surplus;

- Using battery systems to store the power generation surplus, supplying it to the grid further when no voltage rise happens.

These approaches are addressed in the following sections.

\section{A. PMSG speed control to decrease aerodynamic efficiency}

In normal operating conditions, the control scheme governing the dc-dc boost converter allows controlling the switching duty cycle such that, based on a proper reference speed, the determined values of dc voltage and current correspond to the maximum electromagnetic torque. The inverter dc voltage remains constant set by the grid voltage, by balancing the input and output power in the dc-link. Thus, controlling the active power delivered to the grid following a voltage rise can be performed by adjusting the rotor reference speed, such that the tip speed ratio will be decreased. For this purpose an high level control functionality is included in the control scheme of the dc-dc boost converter, as it can be observed from Fig. 4.

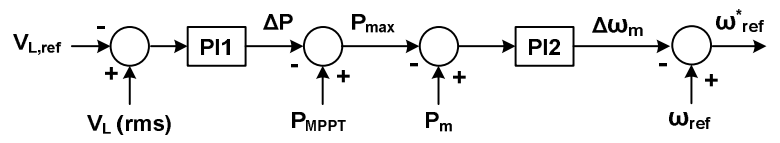

Fig. 4: Additional control functionalities for dc-dc boost converter control structure aiming to provide voltage control.

If the grid voltage is higher than its maximum allowable value (typically 1,1 p.u), the control structure based on PI regulators will adjust the speed deviation, $\Delta \omega_{m}$, from the optimal shaft speed, $\omega_{\text {ref }}$ in order to derive a proper speed reference, $\omega^{*}$ ref. Thus, based on the grid voltage error, the first control loop determines the turbine output power surplus, $\Delta P$, in order to define a less efficient operating point, $P_{\max }$, corresponding to the maximum power that can be extracted from the turbine. The corresponding reference speed, $\omega^{*}$ ref, is then adjusted through the PI2 controller, which will be decreased in order to assure the system operation in the non stall region and, hence, the system stability. Therefore, the dc- 
dc boost converter control scheme will control the PMSG electromagnetic torque by tracking the provided speed reference, instead of tracking the speed reference corresponding to the optimum tip speed ratio.

\section{B. Using the dump load to dissipate the generation surplus}

In this approach it is assumed that the PMSG based micro wind generation system is controlled to be operated at the maximum power point. So, when it is necessary to perform voltage control on the LV grid, the active power delivered to the grid should be limited, being the generation surplus dissipated in the dump load.

For security issues, the dump load has been commonly used for shedding mechanical power under abnormal operating conditions, being connected to the dc-link of the grid side VSI [28], as it can be observed from Fig. 5. However, with additional control functionalities, it can also be exploited to prevent high voltage problems in LV networks.

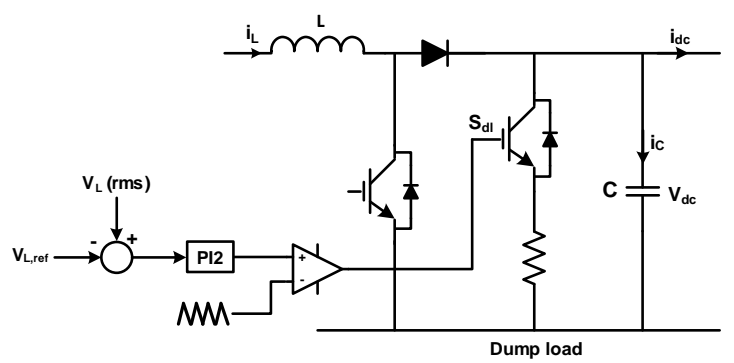

Fig. 5: Additional control functionalities to provide voltage control exploiting the dump load.

As it can be observed from Fig. 5, when the grid voltage rises above a given reference, the voltage controller based on a PI regulator is used to adjust the reference signal that will define the switching duty cycle, $S_{d l}$, and therefore the control pulses of the switching power device.

\section{Using a battery system to store the generation surplus}

Instead of exploiting the dump load to dissipate the generation surplus, in this proposed approach the energy corresponding to the generation surplus is stored in a battery system in order to be further delivered to the grid when no high voltage problems arise. The battery is connected to the dc-link of the VSI side through a bidirectional PWM dc-dc buck converter, as depicted in Fig. 6.

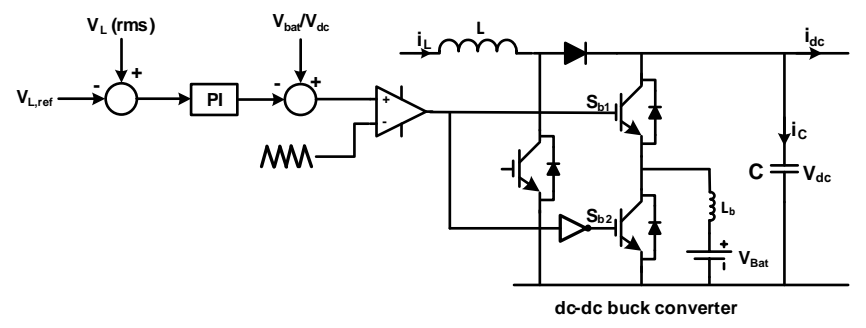

Fig. 6: Additional control functionalities to perform voltage control using a battery connected to the dc-dc buck converter.

The additional control functionalities allow exploiting the battery system to provide grid voltage regulation according to the specified voltage reference. Thus, during the time periods when the grid voltage is higher than the corresponding reference, the control system transfers the generation surplus to the battery by controlling the switching duty cycle of the $\mathrm{dc}$-dc converter. Otherwise, the energy stored in the battery is transferred to the LV network through the VSI, by controlling the power balance to the dc-link.

In this approach additional control systems are required to manage the battery charging and discharging procedures. Also, the battery should be carefully sized. However these subjects are not addressed in this research.

\section{Simulation RESUltS AND DisCUSSION}

In order to evaluate the performance of the proposed control strategies a small test system was implemented in Matlab $^{\circledR} /$ Simulink $^{\circledR}$, comprising a three-phase, 3500W, 250 rpm PMSG with 20 poles and the corresponding power electronic interfaces together with the control schemes described previously, being the single-phase VSI connected to a $400 \mathrm{~V}$ network with a low $\mathrm{X} / \mathrm{R}$ ratio. The single-phase micro wind generation system equipped with a PMSG is connected to the phase $a$ of the LV network operating under unbalanced conditions. This test system is presented in Fig. 7.

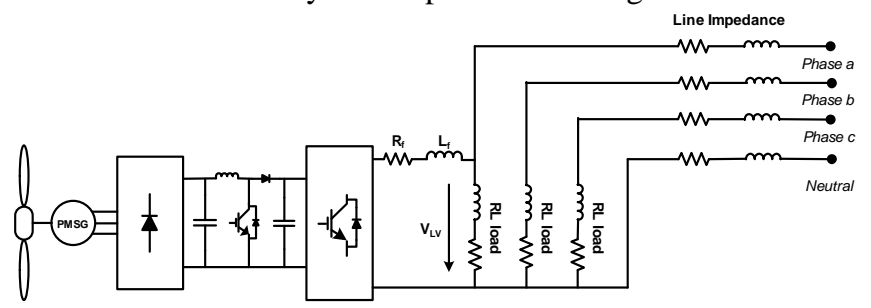

Fig. 7: The test system with the PMSG driven wind turbine

For variable speed operation, the mechanical output power versus rotor angular speed characteristic of the PMSG driven wind turbine was used in the MPPT algorithm in order to derive the target rotor speed. These power curves are presented in Fig. 8, for several incoming wind speeds [7].

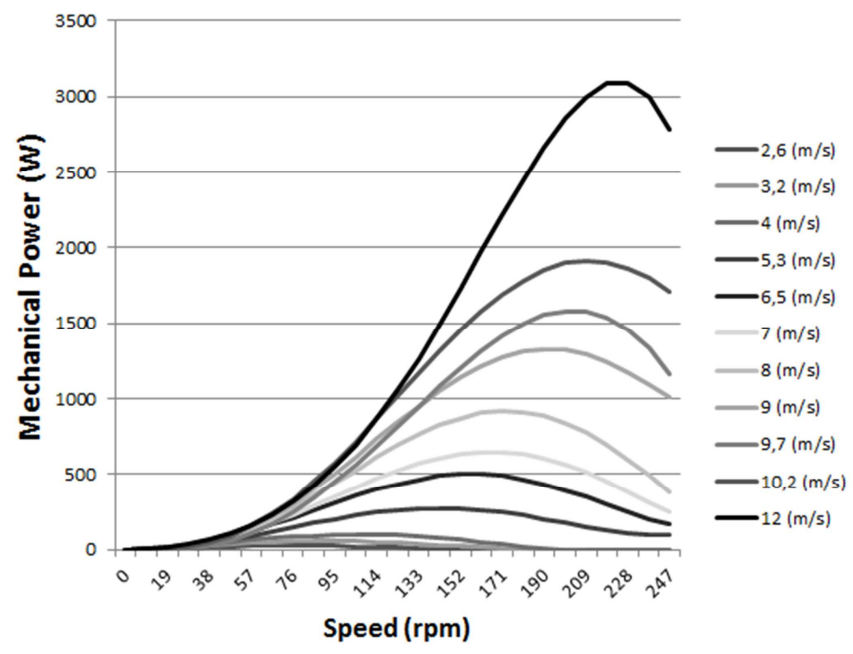

Fig. 8: Mechanical output power versus rotor angular speed characteristic. 
For simulation purposes it was also considered that the PMSG driven wind turbine is subjected to the wind speed behavior represented in Fig. 9.

The results obtained are presented and discussed in the following sections. It was assumed that the maximum allowable voltage per phase is 1,1 p.u $(253 \mathrm{~V})$.

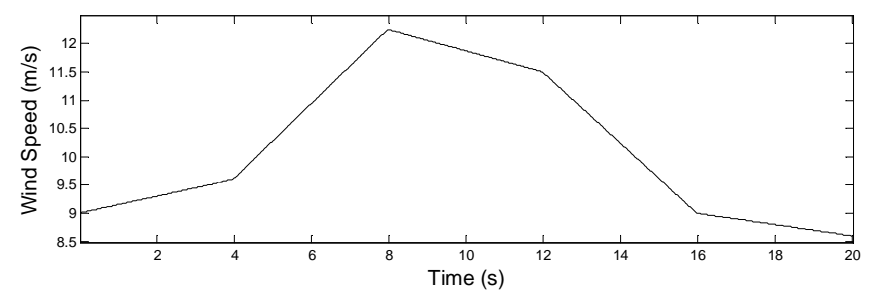

Fig. 9: Incoming wind speed behavior

\section{A. Controlling the PMSG speed to perform voltage control}

The dynamic behavior of the PMSG driven wind turbine following the considered wind speed variations is represented in Fig. 10 and Fig. 11. A comparison is also provided regarding the results obtained considering that the system is always operated by tracking the optimum tip speed ratio and considering the additional control functionalities aiming to perform grid voltage control by regulating the PMSG speed.

Following the wind speed variations, the PMSG speed is adjusted for maximum extraction power and, hence, more active power is delivered to the grid as the wind speed increases, resulting in voltage rise above 1,1 p.u. for several seconds. Therefore, in this time period, the additional control functionalities take action by controlling the PMSG speed to track the derived shaft speed reference that regulates the grid voltage for 1.1 p.u. by decreasing the aerodynamic efficiency, such that the turbine output power is reduced limiting thus the active power delivered to the grid, as it can be observed from Fig. 10.
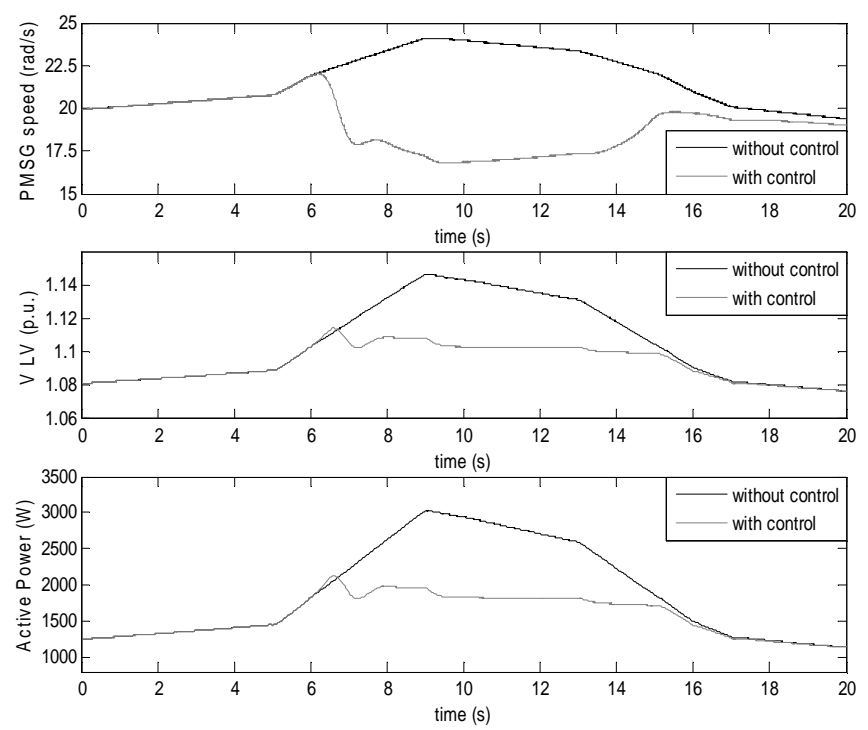

Fig. 10: Dynamic behavior of the PMSG driven wind turbine including the PMSG rotor speed, grid voltage and active power delivered to the LV grid
The control scheme implemented in the dc-dc boost converter controls the PMSG electromagnetic torque by regulating the current in the inductance of the converter, according to the provided speed reference, thereby regulating the dc-link voltage at the diode rectifier side. Thus, when the speed reference is derived to regulate the grid voltage for 1.1 p.u., the electromagnetic torque is decreased following a less efficient operating point and both the current in the inductance and the dc-link voltage at the diode rectifier side behave accordingly, as it can be observed from Fig. 11. The dc-link voltage at the VSI side is regulated to its reference value, 500 $\mathrm{V}$, by means of the control scheme implemented in the VSI that tries to balance the input and output power to the dc-link.
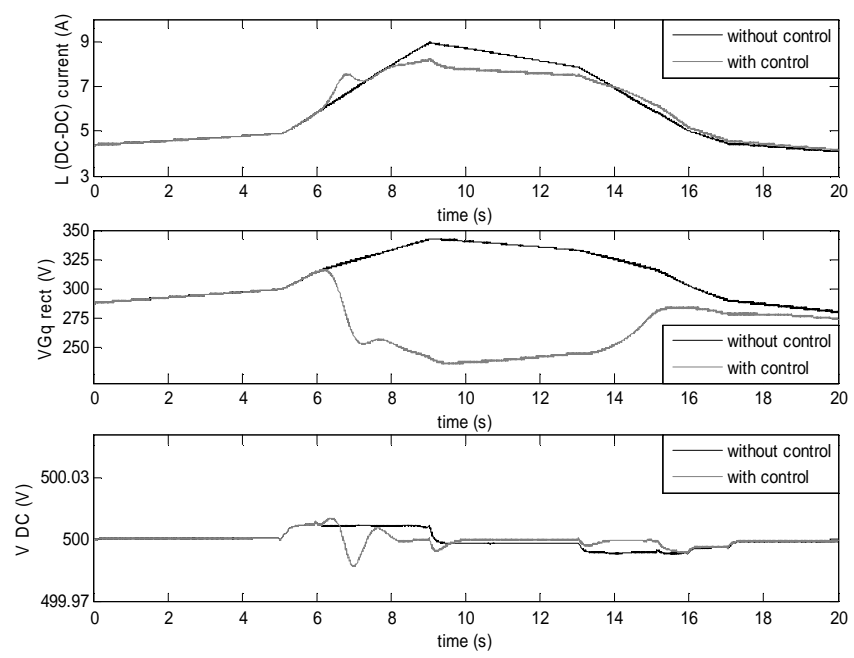

Fig. 11: Dynamic behavior of the dc-dc boost converter, including the current in the inductance, the dc-link voltage of the diode rectifier side and the dc-link voltage of the VSI side
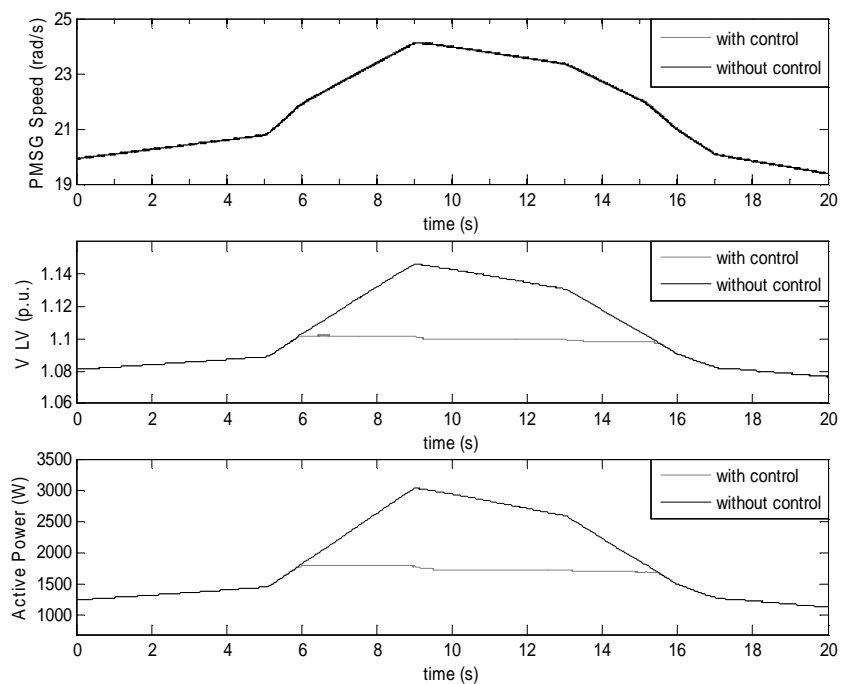

Fig. 12: Dynamic behavior of the PMSG driven wind turbine exploiting the dump load to perform voltage control, including PMSG rotor speed, grid voltage and active power delivered to the grid.

It should be noted that when the additional voltage control functionality takes action small transients are experimented. According to the PMSG dynamics and system inertia, when the rotor speed is reduced part of the kinetic energy is 
converted to electrical power, leading with a small transient peak current in the inductance of the dc-dc boost converter, which will increase the dc-link voltage of the VSI side. However, since the VSI enables fast control of active power, a small amount of active power is delivered to the LV grid resulting in a small transient voltage rise.

After this small transient period the grid voltage is effectively controlled to the desired value, demonstrating thus the effectiveness of the proposed control strategy.

\section{B. Exploiting the dump load to perform voltage control}

The results obtained using the grid voltage control approach, exploiting the dump load to dissipate the generation surplus, are presented in Fig. 12.

In this case the rotor speed of the PMSG tracks the optimum tip speed ratio, but when the grid voltage rises, a given part of the active power, which is derived from the control scheme to perform voltage regulation, is dissipated in the dump load, limiting thus the active power delivered to the LV grid in order to prevent high voltage problems. The grid voltage is kept within limits, as it can be observed from Fig. 12, demonstrating thus the effectiveness of the proposed control scheme.

\section{Voltage control using a battery system}

When the battery is used to store the generation surplus, the PMSG based micro wind generation system is operated with maximum power coefficient for all wind speeds. Thus, during the time periods when it is necessary to provide voltage control by limiting the active power delivered to the grid, the generation surplus is stored in the battery, increasing thus its state of charge. Therefore, the grid voltage is kept at 1.1 p.u., as it can be observed from Fig. 13.
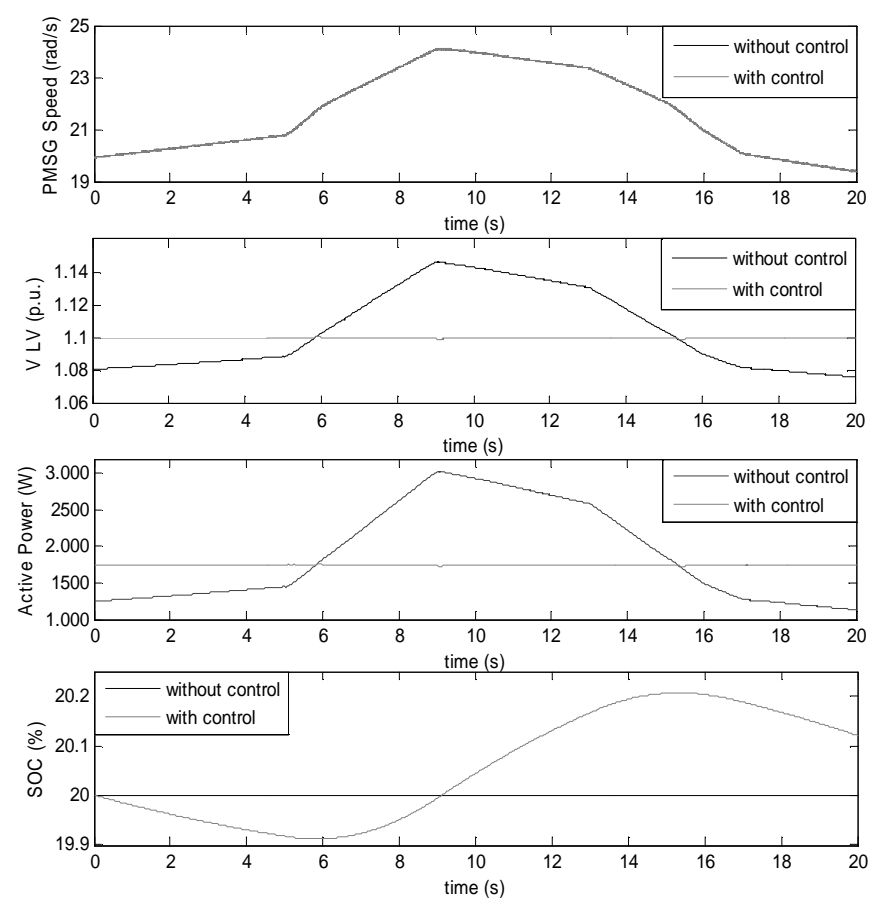

Fig. 13: Dynamic behavior of the PMSG driven wind turbine a battery system to perform voltage control, including PMSG rotor speed, grid voltage and active power delivered to the grid and state of charge of the battery.
The stored energy is delivered to the grid when the operating conditions make it possible, that is, when voltage will be below the maximum allowable value. However, in this case, as the control scheme aims to regulate the grid voltage for 1.1 p.u., the active power provided from the battery is controlled such that the voltage is kept to its reference until the minimum state of charge is reached.

\section{CONCLUSIONS}

In this paper three control strategies based approaches were proposed aiming to control the active power delivered to the grid by PMSG based micro wind generation systems in order to prevent high voltage problems following increasing integration levels of these microgeneration systems in LV networks. The performance of the additional control functionalities aiming to perform voltage control was evaluated through numerical simulations and the results obtained allow verifying the effectiveness and technical feasibility of the proposed approaches. Controlling the PMSG speed to perform voltage control is a cost effective solution since no additional equipment is required. However, more research is required in order to obtain a cost benefit tradeoff involving all the proposed control schemes.

The implementation of these control strategies will contribute to improve the operating conditions of LV networks and future MicroGrids by increasing the system robustness following a large scale integration of microgeneration systems exploiting RES.

\section{REFERENCES}

[1] M. Sánchez-Jiménez, "Smart Electricity Networks: European drivers and projects for the integration of RES and DG into the electricity grids of the future," presented at 3rd European Conference PV-Hybrid and Mini-Grid, Aix en Provence, France, 2006.

[2] M. W. Davis, "Distributed resource electric power systems offer significant advantages over central station generation and T\&D power systems. I", Proc. of 2002 IEEE Power Engineering Society Summer Meeting, vol. 1, pp. 54-61, July 2002.

[3] M. W. Davis, "Distributed resource electric power systems offer significant advantages over central station generation and T\&D power systems. II", Proc. of 2002 IEEE Power Engineering Society Summer Meeting, vol. 1, pp. 62-69, July 2002.

[4] J. A. Peças Lopes, C. L. Moreira, A. G. Madureira, "Defining control strategies for microgrids islanded operation", IEEE Transactions on Power Systems, vol. 21, n. 2, pp. 916-924, May 2006.

[5] C. L. Moreira, F. O. Resende, J. A. Peças Lopes, "Using low voltage microgrids for service restoration", IEEE Transactions on Power Systems, vol. 22, nº. 1, pp. 395-403, February, 2007.

[6] B. Gwisdorf, T. Borchard, T. Hammerschmidt, C. Rehtanz, "Technical and economic evaluation of voltage regulation strategies for distribution grids with a high amount of fluctuating dispersed generation units," Proc. of 2010 IEEE Conference on Innovative Technologies for an Efficient and Reliable Electricity Supply (CITRES), pp. 8-14, Sept. 2010.

[7] A. P. N. Matos, "Control of the injected active power in LV networks by micro wind generation systems" (in Portuguese), Msc. Thesis, Faculty of Engineering of Porto University, Porto, 2010.

[8] S. Vlachopoulos, C. Demoulias, "Voltage regulation in low-voltage rural feeders with distributed PV systems", in Proc. 2011 IEEE EUROCON International Conference on Computer as a Tool, pp. 1-4, April 2011.

[9] S. H. Song, S. Kang, N. Hahm, "Implementation and control of grid connected AC-DC-AC power converter for variable speed wind energy conversion system", in Proc. of Eighteenth Annual IEEE APEC '03 Applied Power Electronics Conference and Exposition, vol.1, pp. 154158, Feb. 2003. 
[10] Y. Higuchi, N. Yamamura, M. Ishida, T. Hori, "An improvement of performance for small-scaled wind power generating system with permanent magnet type synchronous generator", in Proc. of the 26th Annual Conference of the IEEE Industrial Electronics Society, IECON 2000, vol.2, pp.1037-1043, 2000

[11] Qingling He, Xiaohua Bao, Qunjing Wang, "Analyzing on structure parameters for low-speed permanent magnet synchronous generator", in Proc. of ICEMS 2008 International Conference on Electrical Machines and Systems, pp.3060-3063, 2009.

[12] N. Bianchi, A. Lorenzoni, "Permanent magnet generators for wind power industry: an overall comparison with traditional generators", in Proc. International Conference on Opportunities and Advances in International Electric Power Generation, pp. 49-54, 2002.

[13] Hyong Sik Kim Lu, D.D.-C., "Review on wind turbine generators and power electronic converters with the grid-connection issues" in Proc of 2010 20th AUPEC Australasian Universities Power Engineering Conference, pp.1-6, 2010

[14] A. Mirecki, X. Roboam, F. Richardeau, "Architecture complexity and energy efficiency of small wind turbines", IEEE Transactions on Industrial Electronics, vol. 54, no. 1, pp. 660-670, 2007

[15] J. M. Dores Costa, N. Pimenta, R. Rei, F. Cardoso, P. Chaves, "Smallpower wind turbine system for urban applications", EWEC 2008, European Wind Energy Conference \& Exhibition, Brussels, 2008.

[16] J. A. Baroudi, V. Dinavahi, A. M. Knight, "A review of power converter topologies for wind generators", in Proc. of 2005 IEEE International Conference on Electric Machines and Drives, pp. 458-465, 2005.

[17] Z. Chen, E. Spooner, "Grid Power Quality with Variable Speed Wind Turbines", IEEE Transactions on Energy Conversion, vol. 16, no. 2, pp $148-154,2001$

[18] Z. Chen, E. Spooner, "Grid interface options for variable-speed permanent magnet generators", IEE Proc. Electric Power Applications, vol. 145, no. 4, pp. 273-283, 1998.

[19] Z. Chen, E. Spooner, "Wind turbine power converters: A comparative study", in Proc. of $7^{\text {th }}$ International Conference on Power Electronics and Variable Speed Drives, no. 456, pp. 471-476, 1998.

[20] M. H. Rashid, "Power Electronics Handbook", Academic Press, 2nd ed., 2007.

[21] H. Park, D. Lee and H. Kim, "Cost-Effective Converters for Micro Wind Turbine Systems using PMSG", Journal of Power Electronics, vol. 8, no. 2, pp. 156-162, 2008

[22] L. L. Freris, "Wind Energy Conversion Systems", Englewood Cliffs, NJ. Prentice-Hall, 1990

[23] F. S. Reis, K. Tan, S. Islam, "Using PFC and trap filters for harmonic mitigation in wind turbine energy conversion systems", in Proc. of AUPED 2004 Australasian University Power Engineering Conference, 2004

[24] K. Tan, S. Islam, "Optimum control strategies in energy conversion of PMSG wind turbine systems without mechanical sensors", IEEE Transactions on Energy Conversion, vol. 19, no. 2, pp. 392-400, 2004

[25] O. Fethi, L.-A Dessaint, K. Al-Haddad, "Modeling and simulation of the electric part of a grid connected microturbine", in Proc of 2004 IEEE Power Engineering Society General Meeting, vol. 2, pp.2212-2219, 2004.

[26] R. Esmaili, L. Xu, D. K. Nichols, "A new control method of permanent magnet generator for maximum power tracking in wind turbine application", in Proc. of 2005 IEEE Power Engineering Society General Meeting, vol. 3, pp.2090-2095.

[27] N. Mohan, T. M. Undeland, W. P. Robbins, "Power Electronics: Converters, Applications and Design", John Wiley \& Sons, $2^{\text {nd }}$ ed. 1995

[28] M. E. Haque, M. Negnevitsky, K. M. Muttaqi, "A novel control strategy for a variable speed wind turbine with a permanent magnet synchronous generator", IEEE Transactions on Industry Applications, vol. 46, no. 1, pp. 331-339, 2020

\section{BIOGRAPHIES}

Justino Rodrigues received the Integrated Master degree in Electrical and Computer Engineering-Renewable Energy in the Faculty of Engineering of the University of Porto - FEUP (2010). Currently, he is research fellow in INESC TEC since December 2010, being involved in project REIVE (Smart Grids with Electric Vehicles). Currently he is particularly involved on study, development and testing of solutions and pre-industrial prototypes for the active and intelligent control of low voltage distribution networks with large scale integration of micro-generation systems. 